\title{
Early delayed hypersensitivity responses in tuberculin skin tests after heavy occupational
} exposure to tuberculosis

\author{
J H Gibbs, J M Grange, J Swanson Beck, E Jawad, R C Potts, G H Bothamley, \\ T Kardjito
}

\begin{abstract}
The early (six hours) reaction to tuberculin skin testing was studied in 33 Indonesian hospital workers with frequent occupational exposure to $M$ tuberculosis and compared with responses maximal at the usual time (48 hours) in factory workers, from the same locality but with only occasional occupational exposure, to determine the nature of the early reaction. The early reaction had the same general histopathological appearance as that seen in the conventional (48 hour) reaction, and both had an infiltrate consisting largely of $T$ lymphocytes and macrophages. The cell densities were lower in the six hour reactions, but the relative concentration of macrophages was greater in the earlier response. These histometric measurements suggested that the six hour reaction was an accelerated delayed hypersensitivity reaction. Moreover, the absence of a specific IgE response or of particulate masses of $\mathbf{I g}$ or complement, made it unlikely an anaphylactoid or Arthus-type reaction could have been responsible.

It is concluded that those with frequent occupational exposure to $M$ tuberculosis have larger numbers of circulating $T$ cells reactive with mycobacterial antigens, so that the development of the skin test response to tuberculin is less dependent on "by-stander" cell infiltration to mediate the delayed hypersensitivity reaction than the reactions in those with less intense and less frequent natural exposure. The skin test response maximal at six hours is probably a hyperimmune reaction to an antigen recognised by $T$ cells.
\end{abstract}

The positive tuberculin skin test response usually becomes apparent as an area of erythema and dermal induration at 18-24 hours, and reaches a maximum at $48-72$ hours. The erythema fades rapidly, but the induration may persist for weeks, particularly when the reaction is strong. ${ }^{1}$ Some people show intense erythema and itching that is clearly apparent by six hours: this type of reaction is often observed in patients with tuberculosis, ${ }^{2}$ and it is particularly common and intense in hospital staff exposed to patients with overt tuberculosis. $^{3-5}$ By contrast, the six hour reaction is rarely observed in other healthy subjects who are tuberculin positive at 48 hours. The pathogenesis of the six hour reaction has not yet been determined, but its timing would initially suggest an immune complex mediated Arthus (type III) reaction, and there is no experimental evidence on which to exclude a delayed onset IgE mediated (type I) reaction or an accelerated cell mediated delayed hypersensitivity (type IV) reaction.

Particularly intense in hospital workers who remain healthy despite frequent exposure to patients with overt tuberculosis, the early six hour erythematous reaction may be relevant to protective immunity.

\section{Methods}

The study was performed on 33 healthy employees (six men and 27 women, aged 21 to 53 years, mean 31 years) of the William Booth Hospital in Surabaya, Indonesia, whose occupations (nurses, domestic staff, and porters) brought them into frequent contact with patients, many of whom had open tuberculosis. As controls with no occupational exposure, 31 workers (24 men and seven women, aged 21 to 62 years, mean 41 years) were recruited from the staff of a factory at Surabaya. Twenty five hospital workers and 14 factory workers had been immunised with Bacille Calmette-Guérin (BCG), mostly between the ages of 7 and 10 years. All subjects were residents of East Java and had clear chest radiographs. The subjects were fully informed volunteers. The project had been approved by the ethics committee of the Faculty of Medicine and Dentistry of the University of Dundee and the Professoriate of the Faculty of Medicine of Arlangga University, Surabaya, Indonesia.

Each subject was injected intradermally with $0.1 \mathrm{ml}$ of New Tuberculin, a filter sterilised ultrasonicate of $M$ tuberculosis containing $2 \mu \mathrm{g}$ protein $/ \mathrm{ml}^{6}{ }^{6}$ on the volar aspect of both forearms. The skin test sites were examined at six hours when the extent of erythema in the hospital workers was measured in two axes with a ruler, and blood flow velocity was measured by the laser Doppler technique. A biopsy specimen of the test site on the left forearm was taken with a $4 \mathrm{~mm}$ disposable punch (Stiefel Laboratories, Slough, England) and the biopsy core was immediately snap frozen at $-70^{\circ} \mathrm{C}^{7}$ The skin test sites on the right forearm were examined at 48 hours and the extent of induration was measured by the ball-point method in two 
axes. ${ }^{8}$ A punch biopsy specimen was taken from the skin test site on the right forearm of the factory workers.

The dermal blood flow velocity was measured transcutaneously with a laser Doppler velocimeter (PF2, Perimed, Stockholm, Sweden) and the output recorded with a pen recorder. The details of the method and the machine settings have been described previously. 'The machine is internally standardised for consistent performance and the output voltage (RBCflux) is related linearly to the mean blood flow velocity in the cutaneous microcirculation ${ }^{1011}$ : the output signal $(\mathrm{V})$ was recorded on a chart recorder (SE120, BBC, Goetz Metrawatt, Austria).

Care was taken to avoid thawing of the biopsy specimens during transport to Dundee where $6 \mu \mathrm{m}$ sections were cut in a cryostat and stained with haematoxylin and eosin for general histological examination. The presence of plasma proteins in the tissues was sought by direct immunofluorescence under epi-illumination with blue-violet light after staining with fluorescein isothiocyanate conjugated polyclonal antibodies to IgG, IgM, IgA, fibrinogen/fibrin and $\mathrm{C} 3 / \mathrm{C} 3 \mathrm{a}$ (Hoechst UK). The localisation of the various immunologically competent cell types in the inflammatory exudate was shown immunocytochemically with murine monoclonal antibodies to $\mathrm{CD} 3$ (pan $\mathrm{T}$ cells), CD4, and CD8 $\mathrm{T}$ cell subsets, CD25 ("activated" cells bearing the $\mathrm{I} 12$ receptor), CD68 (macrophages) and $\mathrm{CD} 1$ (Langerhans' cells) (Dako Ltd, High Wycombe, England). The bound monoclonal antibody was labelled by the VectaStain biotin-avidin-peroxidase system (Vector Laboratories, Peterborough, England) and visualised histochemically after the addition of diaminobenzidene to produce a brown product. ${ }^{7}$ The various cell types in the dermis were counted in monochrome photographic prints by methods described previously. ${ }^{712}$ For comparison of the results obtained from different sections, the counts of infiltrating cells were expressed as number $/ \mathrm{mm}^{2}$ and the density of epidermal Langerhans' cells was expressed as number $/ \mathrm{mm}$ of the basement membrane.

Blood was taken from all participants by venepuncture at the time of skin testing and serum was separated by clotting and centrifugation and frozen at $-20^{\circ} \mathrm{C}$. The serum samples were transported to London on solid carbon dioxide and then stored at $-40^{\circ} \mathrm{C}$. Serum IgG, IgA, and IgM classes were determined by laser nephelometry and that of IgE with a Pharmacia radioimmunoassay kit. Specific antibody in the IgE class to BCG, an organism almost identical antigenically with virulent $M$ tuberculosis, was assayed by a radioallergosorbent test (RAST), as described previously. ${ }^{13}$

The Mann-Whitney non-parametric test was used to determine the significance of the differences in means for the various measurements, as these were not symmetrically distributed. The differences in rates of BCG immunisation were compared by the $\chi^{2}$ test. All calculations were performed with the Statgraphics package (Version 3.0, STSC Inc, Rockville, Maryland, USA) on a microcomputer.

\section{Results}

\section{EXTERNAL APPEARANCE}

Erythema was obvious at six hours on the skin over the test site in 31 of 33 hospital workers (extent in positive reactors, mean (SD) diameter $17.8(5 \cdot 1) \mathrm{mm})$; none of the factory workers had erythematous reactions at six hours. Induration was not seen in any of the subjects at six hours. By 48 hours, induration was detected (more than $5 \mathrm{~mm}$ in diameter) in 32 of the 33 hospital workers (mean (SD) diameter of positive reaction $22.9(5.9) \mathrm{mm}$ ) and in all of the 31 factory workers (mean (SD) diameter of positive reaction $14.8(8.3) \mathrm{mm}$ ). This difference between hospital and factory workers in the extent of induration at 48 hours was significant $(p<0.005)$.

\section{BLOOD FLOW VELOCITY}

This was raised over the skin test site at six hours in all the hospital workers, mostly to a moderate level (mean (SD) signal $6.8(2 \cdot 46) \mathrm{v}$ compared with that over undisturbed normal skin (mean (SD) signal $1.09(0.27) \mathrm{v})$. A generally comparable hyperaemia was seen over the antigen injection site in factory workers at 48 hours (mean (SD) signal 6.05 $(2.37) \mathrm{v}$ ). There was no significant difference in the height of the laser Doppler signal between the hospital workers at six hours and the factory workers at 48 hours $(95 \%$ confidence interval for the difference in means was -1.97 to $+0.54 \mathrm{v}$ ). Seven of the 33 hospital workers and two of the 31 factory workers showed central relative slowing ${ }^{14}$ of the circulation over the skin test site at six and 48 hours, respectively, but this difference was not significant $\left(\chi^{2}=2 \cdot 86\right.$, p $<0 \cdot 1)$.

HISTOLOGY OF SIX HOUR REACTION IN HOSPITAL WORKERS

Generally, the six hour reaction had a cellular infiltrate in the dermis with a microanatomical distribution similar to, but less intense than, that reported previously in $\mathbf{4 8}$ hour reactions to purified protein derivative skin testing in normal European subjects. ${ }^{7}$ It was composed predominantly of mononuclear cells (lymphocytes and monocyte/macrophages) and there were few polymorphonuclear granulocytes. The infiltrates consisted mainly of perivascular foci with a few cells diffusely spread through the dermal connective tissue. The density of the infiltrate was greatest in the papillary dermis and least in the deeper part of the reticular dermis. The dermis was congested and usually noticeably oedematous in the six hour reactions; there was diffuse immunofluorescence staining of immunoglobulins of the IgG, IgM and $\operatorname{IgA}$ classes and for fibrinogen/fibrin in the inflammatory oedematous exudates both in perivascular foci and intervening dermis: there was no particulate staining of either $\mathrm{C} 3 / \mathrm{C} 3 \mathrm{a}$ or immunoglobulins indicative of immune complex deposition in the dermis. 

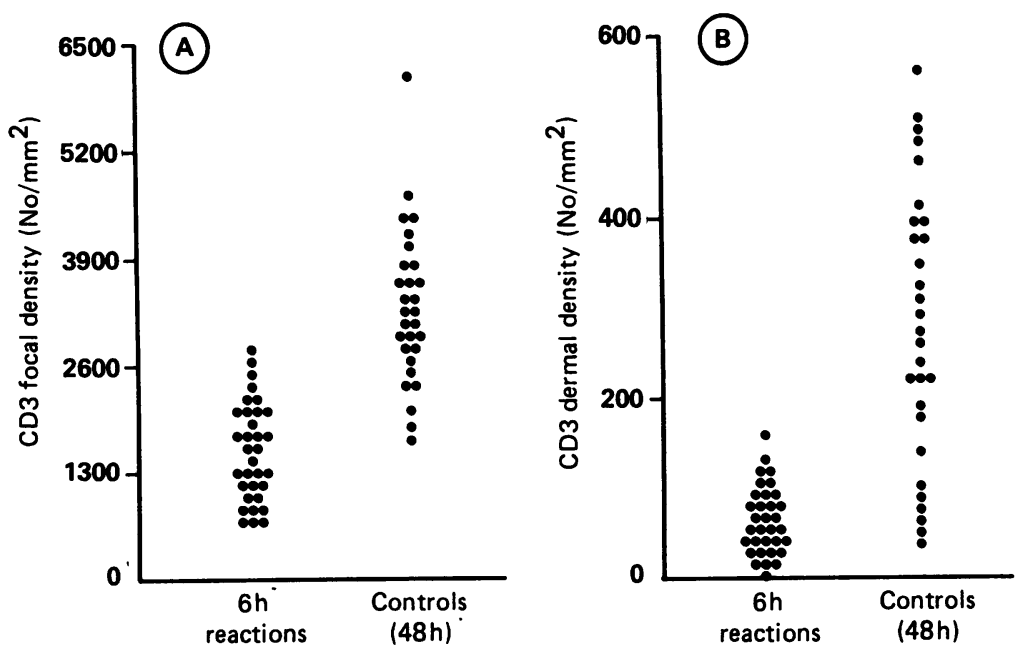

Figure 1 Comparison between hospital workers at six hours and factory worker controls at 48 hours in respect of CD3 lymphocyte densities in the focal concentration and diffuse infiltrate of the dermis. The early reaction in the hospital workers has proportionately fewer cells even though the external appearances are more intense than those seen in the factory workers at 48 hours.
CD25 antigen) at six hours than in the later reaction.

The monocyte/macrophage density in the focal infiltrate was similar in the six hour and 48 hour reactions $(p>0.2)$ so the ratio of macrophages to lymphocytes was greater in the earlier reactions (fig $2 \mathrm{~A}$ ). The density of macrophages in the diffuse infiltrate was also lower in the six hour reactions, but the extent of this difference was relatively small and the macrophage:lymphocyte ratio was not significantly changed.

The macrophage/monocyte density in the focal areas of the six hour reactions was significantly lower in the seven subjects with central relative slowing of blood flow (mean density 1048 cells $/ \mathrm{mm}^{2}$ ) than in those without such slowing (mean density 1436 cells $/ \mathrm{mm}^{2}$ ). The $95 \%$ confidence interval for the difference between these means is +22 to +753 cells/ $\mathrm{mm}^{2}$ ( $\left.\mathrm{p}<0.05\right)$.

The density of the CD1 (Langerhans') cells in the epidermis was not significantly different in the six hour and $\mathbf{4 8}$ hour reactions (table).

\section{HISTOMETRY}

The results are summarised in the table. The focal infiltrate occupied a smaller proportion of the dermis in the six hour reactions in the hospital workers than in the 48 hour reactions of the factory workers $(p<0.01)$. The packing density of $\mathrm{CD} 3$ (fig 1) lymphocytes and of $\mathrm{CD} 4$ and CD8 subsets in the foci of six hour reactions was also lower than (less than half) that seen in the $\mathbf{4 8}$ hour reaction (for the two major subsets; both $p<0.001)$. The density of both CD4 and CD8 lymphocytes in the diffuse infiltrate was substantially lower in the six hour reactions of the hospital workers than the $\mathbf{4 8}$ hour reactions of the factory workers. Thus the six hour reactions contained fewer lymphocytes while the CD4:CD8 ratio in both the focal and diffuse infiltrates was close to that in the peripheral blood. Moreover, there were many fewer activated lymphocytes (bearing the
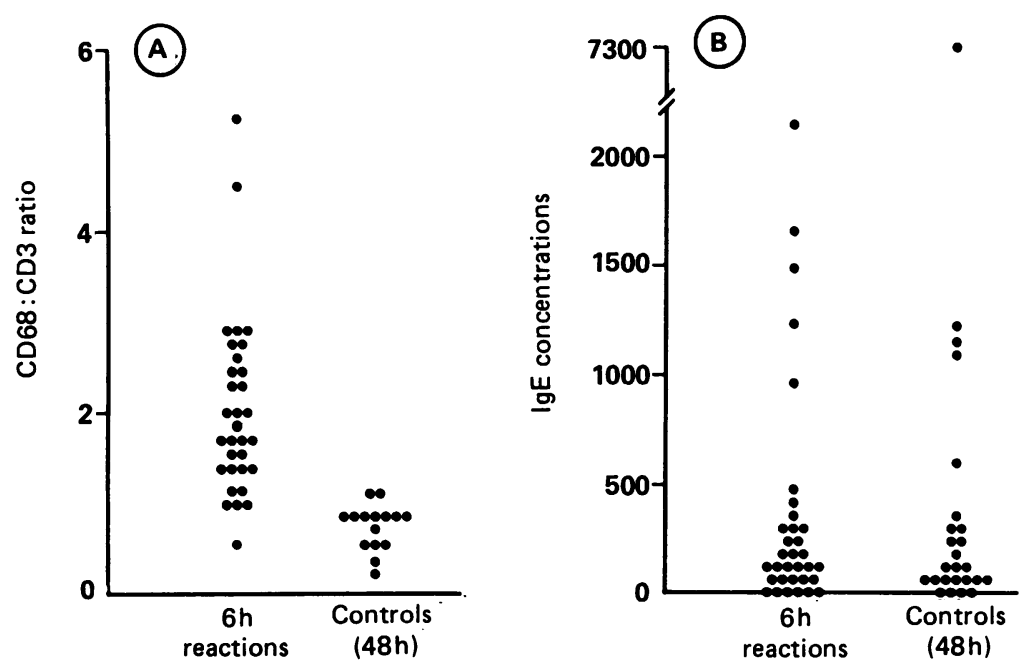

Figure $2 A$ Comparison between counts of all inflammatory cells in sections from tuberculin skin test sites. The ratio density of CD68 (macrophages) cells to that of CD3 ( $T$ cells) was clearly greater in the six hour reactions in hospital workers than in 48 hour responses of factory worker controls (Mann-Whitney $Z$ statistic $4.94 ; p<10^{-6}$ ).

$B$ There are no significant differences between the hospital workers and factory workers in total serum $\operatorname{IgE}$ titres.

\section{SEROLOGICAL STUDIES}

There were no significant differences in the concentrations of total (fig 2B) or specific IgE between the hospital and factory workers. There was a close correlation between the total and $M$ tuberculosis specific IgE titres $(r=0.91)$, but neither measurement showed any correlation with the diameters of the dermal reactions at $\mathbf{4 8}$ hours in either group or in the hospital workers at six hours. The blood flow in the centre of the six hour reactions was slower in the few patients with high specific IgE titre and those with high total IgE titres. Likewise, slower blood flow was recorded in the $\mathbf{4 8}$ hour reactions of factory workers who had higher total and specific IgE titres. The serum concentrations of $\operatorname{IgG}, \operatorname{IgA}$, and $\operatorname{IgM}$ did not differ significantly between the hospital and factory workers.

\section{BCG IMMUNISATION}

There was no clear association between previous BCG vaccination and the occurrence of the six hour reaction to tuberculin. Of the hospital workers, 24 of the 25 who had been vaccinated with BCG, and all of the six who had not been immunised with BCG showed a strong reaction to tuberculin at six hours. None of the 14 vaccinated or 17 non-vaccinated factory workers responded to tuberculin skin testing at six hour.

\section{Discussion}

The six hour reaction to intradermal injection of tuberculin, as seen in apparently healthy hospital workers with frequent and often close contact with tuberculous patients, has an external appearance indistinguishable from the erythematous component of the classic delayed hypersensitivity reaction. Histologically it is the same as the typical 48 hour tuberculin reactions in subjects without excessive exposure to tuberculosis: the cells infiltrating the six hour lesion are of the same types, and 
Summary of histometric measurements made on biopsy specimens of six hour tuberculin reactions and 48 hour tuberculin reactions

\begin{tabular}{|c|c|c|c|c|}
\hline Region of section & Measured feature & $\begin{array}{l}\text { Hospital workers } \\
(n=33) \text { mean }(S D)\end{array}$ & $\begin{array}{l}\text { Factory workers } \\
(n=31) \text { mean }(S D)\end{array}$ & p Value* \\
\hline $\begin{array}{l}\text { Whole dermis (\% of dermis) } \\
\text { Focal infiltrate (number } / \mathrm{mm}^{2} \text { ) } \\
\text { Diffuse infiltrate (number } / \mathrm{mm}^{2} \text { ) }\end{array}$ & $\begin{array}{l}\text { Focal infiltrate } \\
\text { CD4 density } \\
\text { CD8 density } \\
\text { CD4:CD8 ratio } \\
\text { CD25 density } \\
\text { CD68 density } \\
\text { CD4 density } \\
\text { CD8 density } \\
\text { CD4:CD8 ratio } \\
\text { CD25 density } \\
\text { CD68 density } \\
\text { CD1 density }\end{array}$ & $\begin{array}{c}6 \cdot 9(2 \cdot 8) \\
978(369) \\
583(351) \\
2 \cdot 46(1 \cdot 89) \\
19 \cdot 1(26) \\
1353(444) \\
44(25) \\
20(17) \\
2 \cdot 55(1 \cdot 69) \\
1 \cdot 2(1 \cdot 6) \\
256(136) \\
53(20)\end{array}$ & $\begin{array}{c}10 \cdot 3(4 \cdot 9) \\
3657(1667) \\
1662(399) \\
2 \cdot 08(1 \cdot 13) \\
301(186) \\
1662(382) \\
280(197) \\
129(92) \\
2 \cdot 51(1 \cdot 78) \\
18 \cdot 9(15 \cdot 2) \\
374(185) \\
96(174)\end{array}$ & $\begin{array}{l}10^{-4} \\
10^{-11} \\
10^{-11} \\
\text { NS } \\
10^{-8} \\
\text { NS } \\
10^{-11} \\
10^{-11} \\
\text { NS } \\
10^{-8} \\
0 \cdot 03 \\
\text { NS }\end{array}$ \\
\hline
\end{tabular}

^Since the observations in many of the groups had a skewed distribution, the two-way comparisons were tested with the MannWhitney test in the Statgraphics computer package.

largely in the same proportions, as in the later 48 hour reaction. The lack of particulate staining for immunoglobulin or complement components, and the absence of a substantial polymorphonuclear leucocyte infiltration, suggest that the reaction is not due to immune complex formation in the dermis (Arthus reaction). Likewise, the similarity of total and specific IgE titres in hospital and factory workers makes a late type I reaction very unlikely.

The early reaction is much smaller than the later one, both externally and in the percentage of the dermis occupied by perivascular foci and the density of infiltrating lymphocytes in the various dermal compartments. It seems likely, therefore, that the six hour erythematous reaction represents an early or accelerated form of a classic delayed type IV reaction. The blood flow measured over the six hour reaction is raised to a greater extent than that seen at the corresponding time in a classic reaction which reaches its maximum at $\mathbf{4 8}$ hours $^{12}$ and this is reflected by the intense erythema of the early reaction. The repeated occupational exposure to mycobacterial antigen probably leads to increased numbers of antigen specific $T$ cells in the circulation, so that early accumulation of adequate numbers of such cells at the skin test site produce an accelerated clinical response.

The only difference in cell content between the six and 48 hour reactions is the greater proportion of macrophages relative to $T$ cells in the early onset response, but the absolute density of focal macrophages in the former is not significantly different from that in the latter. This may well account for the visible erythematous response at six hours in the hospital workers when the macrophage density becomes sufficiently high to produce the cytokine-mediated erythema. Alternatively a high proportion of macrophages may well be a normal early component of all delayed-type hypersensitivity reactions: we were unable to obtain biopsy specimens at six hours from the factory workers for comparison. In a previous study ${ }^{15}$ the 48 hour reactions of hospital and factory workers (different subjects than in this study) were compared, but no differences were seen between the two groups, either in the overall density or the density gradient of the CD4 and CD8 cells in the dermis, but the number of macrophages was significantly greater in the hospital workers than in the factory workers. Thus increased numbers of macrophages seems to be characteristic of both the six and 48 hour reactions in the hospital workers. The increased macrophage density in tuberculin reactions of hospital workers may be a response to repeated heavy occupational exposure to $M$ tuberculosis resulting in hyperimmunisation and even subclinical, spontaneously healing infection. Effective recruitment of macrophages would assist in granuloma formation with entrapment of the infecting bacilli.

Central relative slowing of the blood flow in tuberculin reactions has been observed previously, particularly in more severe reactions, and was thought to contribute to the necrotic component of the reaction, analogous to the Koch phenomenon in guinea-pigs, and possibly underlying the mechanism of cavity formation in post-primary tuberculosis. ${ }^{14}$ It was of interest, therefore, that seven hospital workers with evidence of central relative slowing at six hours should have had significantly lower numbers of macrophages in the test sites. The cause of central relative slowing is unknown, ${ }^{1416}$ but release of tumour necrosis factor from macrophages ${ }^{17}$ may be involved.

It may seem obvious that an accelerated cellmediated reaction would provide better protection against invading tubercle bacilli. It has, however, been postulated that tuberculin reactions are divisible into either a protective non-necrotic macrophage-activating type or a necrotic type, corresponding to the Koch phenomenon in guinea-pigs, that contributes to the pathogenesis of tuberculosis. ${ }^{618}$ Thus cell mediated reactivity in tuberculosis must be seen as a two-edged sword and it cannot be assumed that an accelerated reaction necessarily provides more effective protection, as is the case in many other types of acute infections where antibody has a crucial protective role. It is, however, possible that the protective cellmediated reaction is more rapidly inducible than the necrotising reaction, leading to the destruction of tubercle bacilli before the later, less protective, reaction begins.

We are most grateful to The Wellcome Trust for financial assistance, the staff of the William Booth Hospital for their cooperation, to Dr JL Stanford for the gift of "New Tuberculin", and to Mrs Rosalind Mitchell for valuable secretarial assistance.

1 Caplin A. The tuberculin test in clinical practice. $A n$ Illustrated guide. London: Bollière Tindall 1980:15. 2 Kardjito T, Grange JM. Diagnosis of active tuberculosis by 
immunological methods. 2. Qualitative differences in the dermal response to tuberculin in patients with active pulmonary disease and healthy tuberculin-positive individuals. Tubercle 1982:63:275-8.

3 El Ansary EH, Grange JM. Qualitative differences in tuberculin reactivity in patients with tuberculosis, occupational culin reactivity in patients with tuberculosis, occupation

4 Kardjito T, Grange JM. A clinical evaluation of the diagnostic usefulness of an early dermal reaction to tuberculin: failure to distinguish between tuberculosis and other respiratory disease. Tubercle $1985 ; 66: 129-32$.

5 Grange JM, Beck JS, Harper El, Kardjito T, Stanford JL. The effect of exposure of hospital employees to patients with tuberculosis on dermal reactivity to four new tuberculins. Tubercle 1986;67:109-18.

6 Stanford JL, Lema E. The use of a sonicate preparation of myobacterium tuberculosis (new tuberculin) in the assessment of BCG vaccination. Tubercle 1983;64:275-82.

7 Gibbs JH, Ferguson J, Brown RA, et al. Histometric study of the localisation of lymphocyte subsets and accessory of the localisation of lymphocyte subsets and accessory
cells in human Mantoux reactions. J Clin Pathol 1984;37: cells in h

8 Sokol JE. Measurement of delayed skin test responses. $N$ Engl J Med 1975;292:501-2.

9 Beck JS, Spence VA. Patterns of blood flow in the microcirculation of the skin during the course of the tuberculin reaction in normal human subjects. Immunology 1988;58:209-15.

10 Nilsson GE, Tenland T, Oberg PA. A new instrument for continuous measurement of tissue blood flow by light beating spectroscopy. IEEE Trans Biomed Eng 1980a;27:12-19.

11 Nilsson GE, Tenland T, Oberg PA. Evaluation of a laser doppler flowmeter for measurement of tissue blood flow. IEEE Trans Biomed Eng 1980b;27:597-604.

12 Beck JS, Morley SM, Gibbs JH, et al. The cellular response of tuberculosis and leprosy patients and of healthy controls in skin tests to "New Tuberculin" and Leprosin A. Clin Exp Immunol 1986;64:484-94.

13 Yong AJ, Grange JM, Tee RC, et al. Total and antimycobacterial IgE levels in serum from healthy subjects and patients with tuberculosis and leprosy. Tubercle 1989;70:273-9.

14 Beck JS, Gibbs JH, Potts RC. Histometric studies on biopsies of tuberculin skin tests showing evidence of ischaemia and necrosis. $J$ Pathol 1989;159:317-22.

15 Morley SM, Beck JS, Brown RA, Grange JM, Kardjito T. Occupational exposure to Mycobacterium tuberculosis and cytology of response to skin testing with new tuberculin. Tubercle 1987;68:71-3.

16 Beck JS, Gibbs JH, Potts RC, et al. The relation between cutaneous blood flow and cell contact in the tuberculin reaction. Scand J Immunol 1989;29:33-9.

17 Rook GAW. Progress in the immunology of the mycobacterioses. Clin Expm Immunol 1987;69:1-9.

18 Stanford JL. Immunologically important constituents of mycobacteria: antigens. In: Ratledge C, Stanford JL, eds. The biology of the mycobacteria Vol 2. London: Academic Press, 1983:85-127.

\section{Eponyms in pathology ...}

BORDET, Jules Jean Baptiste Vincent (1870-1961) was a Belgian microbiologist, born in Soignies, who studied at Brussels, qualifying in 1892 . From 1894 he worked with Metchnikoff at the Institut Pasteur in Paris until he was appointed director of the newly founded Institut Pasteur in Brussels in 1901. His early work investigated bacteriolysis and haemolysis, but his most important research was into what was called "alexin", now known as complement. He showed the diagnostic value of complement fixation tests and an unexpected by-product of this work was the isolation, with Gengou in 1906, of the causative organism of whooping cough, now known as Bordetella Pertussis. In 1907 he was appointed honorary professor of bacteriology in Brussels, and in 1916 a foreign FRS. In 1919 he was awarded the Nobel prize for medicine for his work on complement lysis. 